\title{
Blue Book 2011: Improvements to Household Expenditure Estimates
}

\section{Author Name(s): Peter Gittins and Gareth Clancy, Household Expenditure Branch}

\begin{abstract}
This article explains the impact of improvements to Household Final Consumption Expenditure (HHFCE) estimates between 1997 and 2011 incorporated into data released in Blue Book 2011.
\end{abstract}

\section{Summary}

Blue Book 2011 will introduce large scale changes in IT systems, methods and classifications to National Accounts estimates. These include: a new Standard Industrial Classification - SIC 2007, a new Classification of Products by Activity - CPA 2008, adoption of a new seasonal adjustment model (X-12-ARIMA), changes to deflation methods, including the harmonisation of deflators across the accounts and the move from using the Retail Prices Index for deflation to the Consumer Prices Index, where appropriate.

This article explains the impact of these changes and some other specific method developments for Household Final Consumption Expenditure (HHFCE) estimates between 1997 and 2011. The HHFCE specific developments include: the improvement of adjustments related to foreign tourist expenditure in the UK; the change in the level at which calculations like deflation and seasonal adjustment take place; and the re-classification of a service expenditure from one area of household expenditure to another. In addition, the important impact of balancing household expenditure estimates against other sectors' estimates (Supply and Use balancing using the new SIC 2007 and CPA 2008) is discussed. The article also highlights a number of potential future HFHCE developments.

\section{HHFCE Developments in Blue Book 2011}

Household Final Consumption Expenditure estimates are produced in current prices and chained volume measures using the Classification of Individual Consumption by Purpose (COICOP). Changes to HHFCE estimates introduced in Blue Book 2011 are applied at a detailed good and service level using the COICOP classification.

Improvements to the adjustments applied to take account of expenditure by foreign residents in the UK 
Before Blue Book 2011, upward adjustments were applied to a number of commodities to reflect expenditure by foreign residents visiting the UK, not captured in source data. These adjustments helped produce the HHFCE domestic estimate - i.e. all spending in the UK domestic territory, which includes the exports of services (for example money spent by foreign tourists in the UK). The adjustments were then 'netted-off', along with other foreign residents' expenditure in the UK, to transform the estimate into the HHFCE national estimate - which includes all spending by UK residents whether in UK territory or abroad, but excludes all foreign residents' expenditure in the UK.

These broad adjustments were based on fixed proportions of total foreign tourist expenditure in the UK (which is part of the trade in services estimates).

The Blue Book 2011 method of calculating the tourism adjustments creates a link at a detailed level between COICOPs and Trade in Services estimates. It does this by taking Trade in Services foreign tourist expenditure estimates at a more detailed level (the Classification of Products by Activity - CPA 2008 level used for Supply and Use balancing) and matches it directly to published level COICOPs with tourist expenditure not covered in the source data. This new method has improved the consistency across National Accounts by allocating tourism adjustments to a number of COICOPs that were not previously adjusted. It has also changed the value of the tourism adjustments for some COICOPs.

The changes to tourism uplifts have generally increased HHFCE COICOP estimates, thereby improving the coherence of household expenditure with the supply side of the economy. This in turn has helped improved the consistency between COICOP and CPA 2008 used as part of the balancing process.

\section{Changes in the level of COICOP breakdown used to build up aggregates.}

This change centres on the standardisation and simplification of the HHFCE compilation processes. It is invisible to users because the changes in calculations are at a level below the published estimates. However, calculating at a more (or less) detailed level has an important impact on one of the major changes taking place in Blue Book 2011, the move to deflation using the Consumer Prices Index.

In current price terms, the calculation change has a limited impact for the user at both the aggregate HHFCE and detailed level. However, below the published level the HHFCE system no longer produces some current price estimates. Annex A gives an example of a COICOP that used to have a detailed breakdown to seven current price estimates, but now is only broken down to three, below published level.

For chained volume measures the difference is more apparent. Previously the seven current price estimates were deflated, whereas now deflation is conducted at a more aggregated level, as shown in Annex A.

\section{Re-classification of administrative charges of pensions funds}


The expenditure on administrative charges of pension funds has been reclassified from COICOP 12.5.1 (Life insurance) to 12.6.2 (other financial services). This is a correction of a longstanding misclassification and does not affect the total HHFCE estimate. There are corresponding level shifts (from 1997 onwards) in both the life insurance and other financial services series, in both current and constant prices.

\section{National Accounts Developments affecting HHFCE in Blue Book 2011}

The previous section outlined changes that were specific to HHFCE. This section sets out the work conducted by HHFCE in accordance with the National Accounts framework. These developments have also influenced other areas of the National Accounts.

\section{The Supply and Use balancing process}

Supply and Use tables provide the framework for ensuring supply and demand estimates in the National Accounts system are consistent. They are compiled annually at current prices and use data from the Production, Expenditure and Income approaches to GDP, taking account of the relative strengths of each. The aim of Supply and Use balancing is to produce a coherent and balanced estimate of GDP in current prices.

The Supply tables explain how products are supplied in the domestic economy. The Use tables explain how products are consumed in the form of intermediate and final expenditure by sector. They are compiled based on two identities which together state that total supply in the economy is equal to total demand in the economy. As a component of the expenditure approach, HHFCE estimates, along with other expenditure components, are "balanced" so they equal the production and other supply side estimates.

Supply and Use tables are produced for each industry and for each product within the economy. The 2011 Blue Book data publishes the National Accounts consistent with the UK Standard Industrial Classification of Economic activities 2007 (SIC 2007) and the Classification of Products by Activity 2008 (CPA 2008) for the first time. A Blue Book 2011 Supply and Use article will be published providing more detail on the compilation of Supply and Use tables.

The re-classification of industries and products caused a change in the level at which estimates were processed, which in turn revised the link with COICOP HHFCE estimates. This link which takes the product estimates produced from the Supply and Use process and matches them to the areas of household expenditure is based on a correlation between COICOP and CPA published by Eurostat (see Correspondence Table: COICOP 1999 - CPA 2008).

\section{Seasonal Adjustment in Blue Book 2011}

National Accounts estimates in Blue Book 2011 are seasonally adjusted data using X-12-ARIMA, as opposed to X-11-ARIMA. The main difference between X-11-ARIMA and X-12-ARIMA is the inclusion of the regARIMA facility. This enables real-time estimation of prior adjustment factors, for effects such as outliers, level shifts, Easter and Trading Days. In X-11-ARIMA, these factors had to 
be estimated outside the package, forecasted and imported before seasonal adjustment could begin and were therefore less timely.

In current prices, at the total HHFCE and two-digit COICOP level (for example 01 Food and Drink) the new seasonal adjustment model has had relatively little impact. However, the seasonal adjustment of a small number of lower level products may be sub-optimal in early years (1997 and 1998). This is because the X-12-ARIMA model has been applied to observations from 1997 onwards. Annual totals are not affected. This sub-optimal seasonal adjustment also means some HHFCE detailed quarterly implied deflators may be less reliable in 1997 and 1998.

\section{A new consistent approach to deflation in the National Accounts}

Before Blue Book 2011, a range of existing price indices were used to construct deflators for the components of GDP. The reasons why ONS has improved deflation methods by harmonising the price indices used (where possible) for Blue Book 2011 are set out in Drew (2011). This includes the use of the CPI for deflation of most HHFCE data in preference to the RPI used previously.

Where goods and services are provided to, and consumed by households, a relevant price index is used to deflate the relevant current price series. The RPI has traditionally been used for this purpose, for many years being the only one available. However, CPI has a number of advantages over the RPI for this purpose:

- The CPI is designed to relate to all private and institutional households and foreign visitors to the UK. By contrast, the RPI relates only to private households, and excludes certain segments of the population (e.g. those whose income is within the top four per cent of all households).

- The CPI takes its weights from the breakdown of household expenditure component of the National Accounts rather than from the separate household budget survey (Living Costs and Food Survey) used for RPI.

- The classification framework for the RPI and certain other aspects of its construction are unique to the UK. By contrast, the CPI is produced according to a harmonised methodology across the EU and its use therefore improves international consistency between national accounts volume estimates - international guidance is clear that the CPI should be used.

- The formula used to compute the CPI is predominantly based on a geometric mean whereas the $\mathrm{RPI}$ is computed as an arithmetic mean of price movements. This means that the RPI takes no account of substitution between similar products when one becomes relatively more expensive than others. By contrast, the CPI's formula does allow it to capture this substitution.

Before Blue Book 2011, HHFCE estimates were compiled from 260 data series for current prices. Detailed RPI price indices at this item level were used to deflate these series to produce chained volume measures. Under the new Blue Book 2011system the current price calculations are similar 
in number. However, deflation using CPI is generally at a higher COICOP level. This means that the deflation calculations are now processed on 112 series. The change in deflation balances the conceptual benefits of the $\mathrm{CPI}$ against the reduced detail in comparison with deflation by the RPI. An example of the different level of deflation is shown in Annex A.

\section{Impact on Total HHFCE in Current Prices}

The listed developments that are unique to HHFCE, and those implemented across the National Accounts, all impact on current prices, except the change in deflation methods. However, because the changes have been implemented at a detailed level, or because they have brought the HHFCE estimate closer to the expected Supply and Use balance estimate, there is little overall impact at the aggregate HHFCE level. Total national HHFCE annual revisions on the level are less than 0.1 per cent (of the HHFCE previously published 2011 Q1 estimate) or less than $£ 500$ million in each year up to 2006.

\section{Figure 1: Total HHFCE (national concept) Comparison Q1 2011 and Blue Book 2011}

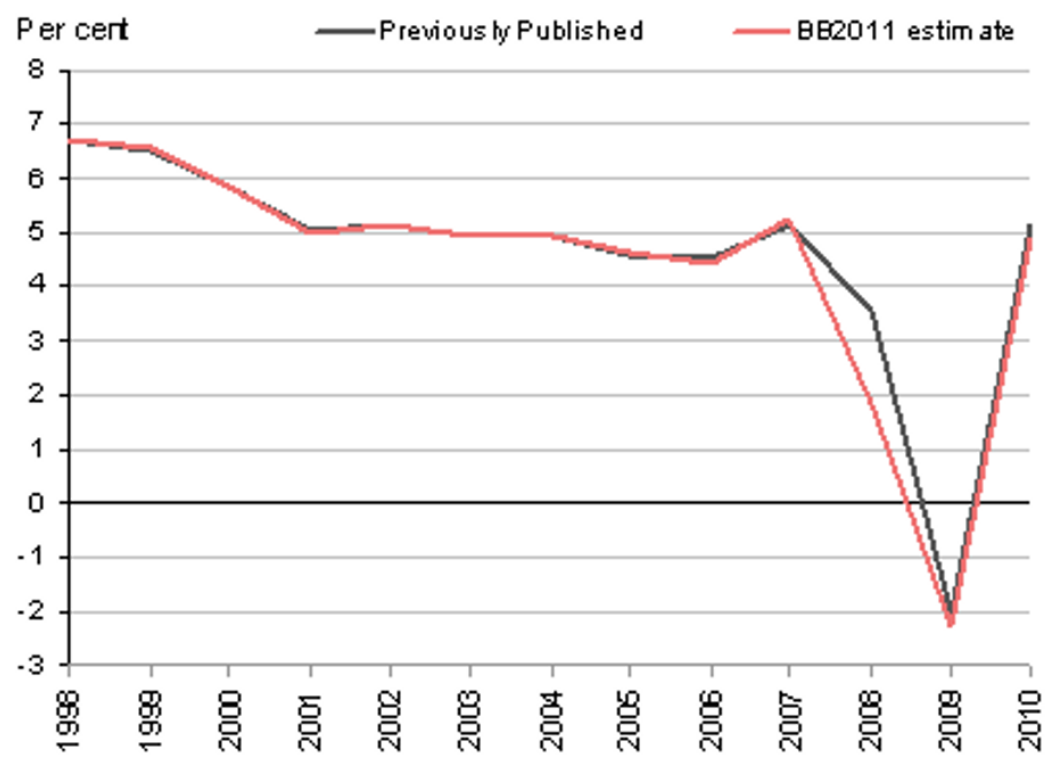

Source: Office for National Statistics

\section{Download chart}

\section{XLS XLS format}

$(13.8 \mathrm{~Kb})$

The small size of the revisions between 1997 and 2006 mean that the differences between Blue Book 2010 and 2011 annual current price growth rates are below 0.1 percentage points (see Figure 1). It is only in the later years that the revisions in HHFCE annual growths have changed significantly. For 2008, the previously published estimate showed growth of 3.5 per cent, but Blue Book 2011 shows growth of 1.8 per cent. The previously published estimate for 2009 was minus 2.0 per cent, while it is minus 2.3 per cent in Blue Book 2011. 
The differences between the two current price datasets can be separated into two periods. The main impact up until 2006 is the improvements in methods and processes applied in constructing HHFCE data, notably changes to the export of services adjustment, which have mostly reduced the overall annual Supply and Use balancing adjustments at the aggregate level (see Figure 2). This indicates that overall, annual HHFCE estimates are now more consistent with the other approaches to measuring GDP (income and output), that they are measured against as part of Supply and Use balancing.

The second period is in 2008 and 2009 where there is an added impact of the reduction in balancing adjustments as a result of the revisions made in the Supply and Use balance to lower the total HHFCE growth in these years. These revisions have been introduced through taking into account new and revised data in from the income and output approaches to GDP (for example HMRC income data for 2008/09 and 2009/10 and Annual Business Survey data for 2009). This is the main cause of the revisions in 2008 and 2009 shown in Figure 1.

\section{Figure 2: Proportion of Supply Use adjustments to total HHFCE (national concept)}

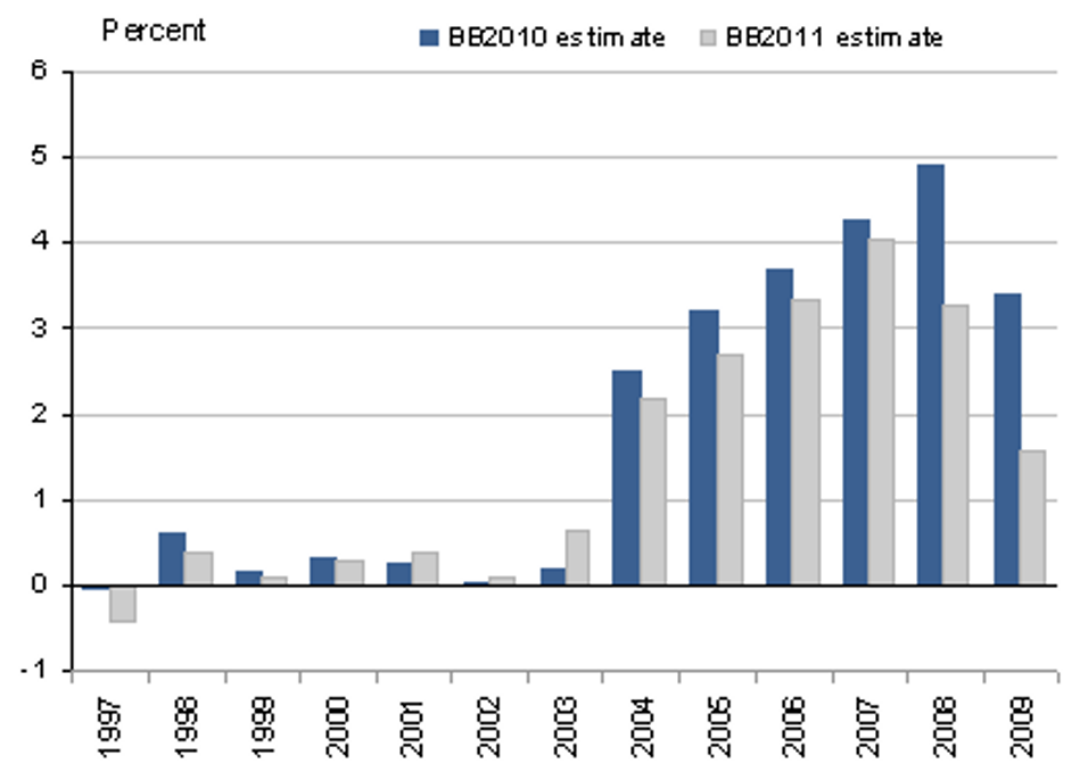

Source: Office for National Statistics

\section{Download chart}

XLS XLS format

$(13.8 \mathrm{~Kb})$

\section{Impact on Quarterly HHFCE Current Prices}

The revisions to the aggregate HHFCE quarterly current price values (seasonally adjusted) are relatively small. This is because the impact of current price revisions at the annual level is limited. Figure 3 shows quarterly percentage growths for national HHFCE seasonally adjusted. The differences are more noticeable in the earlier and later periods. The earlier periods affected slightly by seasonal adjustment and the later periods by Supply and Use balancing. 
Figure 3: Comparison of Q1 2011 and Blue Book 2011 HHFCE growth

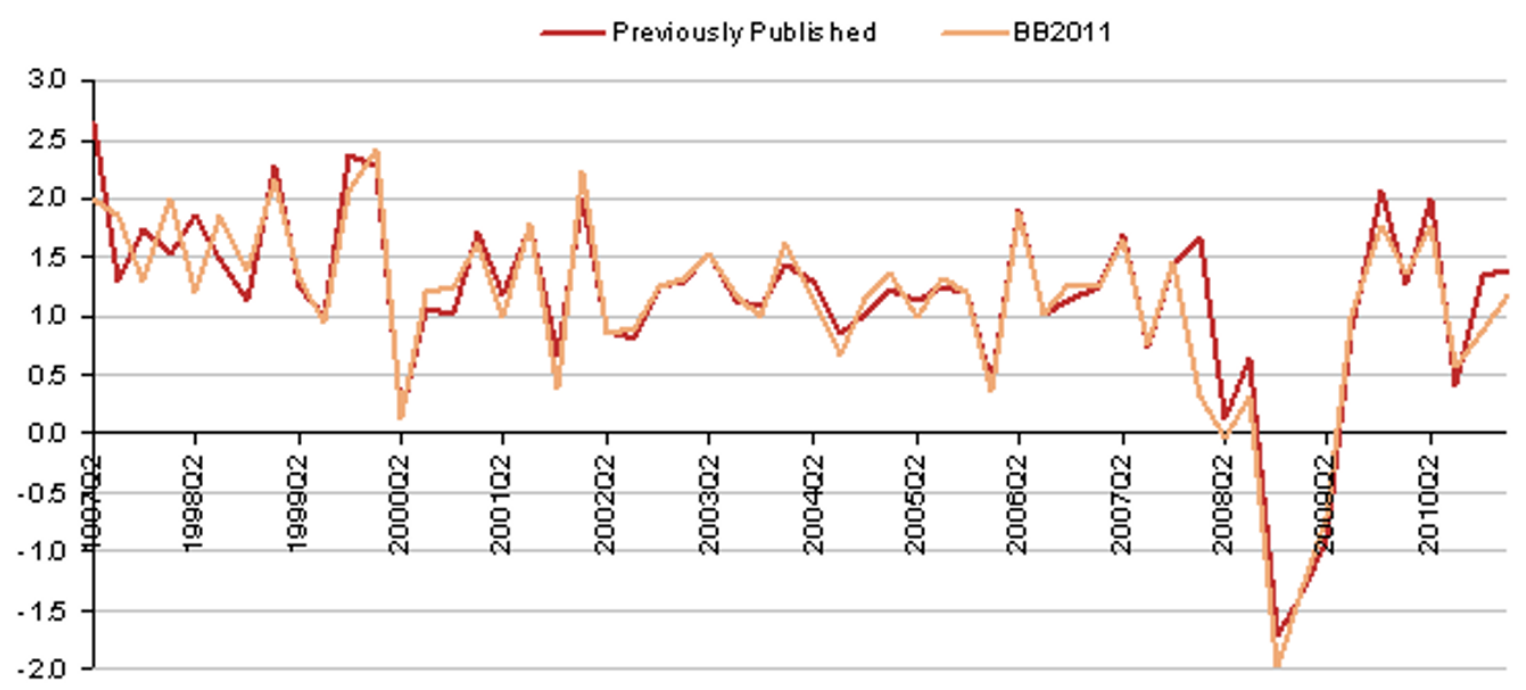

Source: Office for National Statistics

\section{Download chart}

\section{XLS XLS format}

$(16.9 \mathrm{~Kb})$

However, at the aggregate level the revisions to the quarterly paths of the not seasonally adjusted and seasonally adjusted series are mostly similar, confirming that the introduction of X-12-ARIMA has had a limited impact. At the two digit COICOP level the seasonal pattern of data is maintained, although series often show slightly different annual growths as a result of the Supply and Use adjustment process because of the re-distribution of adjustments across COICOPs. This effect is continued and more evident in some of the detailed three and four digit COICOP data.

\section{Impact on Total HHFCE Chained Volume Measures}

The volume growth of HHFCE is an important economic indicator as it feeds into the volume measure of GDP. Changes in current prices can occur because of a change in price or the volume of economic activity. By removing the effect of price changes through deflation it is possible to produce a volume measure. The introduction of the $\mathrm{CPI}$ as the price index to be used for deflation is the most noticeable change affecting the HHFCE chained volume measure (CVM).

However, it is worth recalling how the other changes in methods (already discussed) have also impacted on the HHFCE chained volume measure estimates:

- Revisions to current price data - although in aggregate current price data have not changed significantly, there have been significant revisions at the 4-digit COICOP level (i.e. the level at which deflation takes place). The main changes have been as a result of changes in the Supply and Use balancing adjustments caused through SIC 2007 re-classification; 
- Difference in the level at which deflation is conducted because HHFCE current price calculations are conducted differently in Blue Book 2011;

- The new seasonal adjustment model.

\section{Impact of deflator changes}

It is difficult to fully assess the impact of deflator change because of all the interlinked changes introduced at the same time. However, this section provides analysis conducted to model the impact of the 'pure deflator' changes within a 'steady state' new National Accounts processing HHFCE system. This work isolates (as far as possible) the price indices differences from the processing and current price Supply and Use balancing derived differences. However, it should be remembered that the change in the level at which deflation takes place means that an exact comparison of CPI deflation against RPI deflation is not possible. One reason for this is because RPI deflation was previously carried out at a lower level. In order to conduct deflation at a higher level, comparable with the CPI, the HHFCE implied deflator based on RPI (Blue Book 2010) was used in some cases.

Figure 4 presents the top level HHFCE chained volume measure estimates under three scenarios:

- Blue Book 2010 data re-referenced to a 2008 base and deflated by the RPI;

- Blue Book 2011 data referenced to a 2008 base and deflated by the RPI

- Blue Book 2011 estimates referenced to a 2008 base and deflated using the CPI.

The first two series demonstrate that the difference between Blue Book 2010 data and Blue Book 2011 data is relatively small in comparison to the move to a different price index. It can also be seen that at the aggregate HHFCE level the largest impact of the move to $\mathrm{CPI}$ is in the earlier years. 
Figure 4: Comparison of Total HHFCE chained volume measures by price index

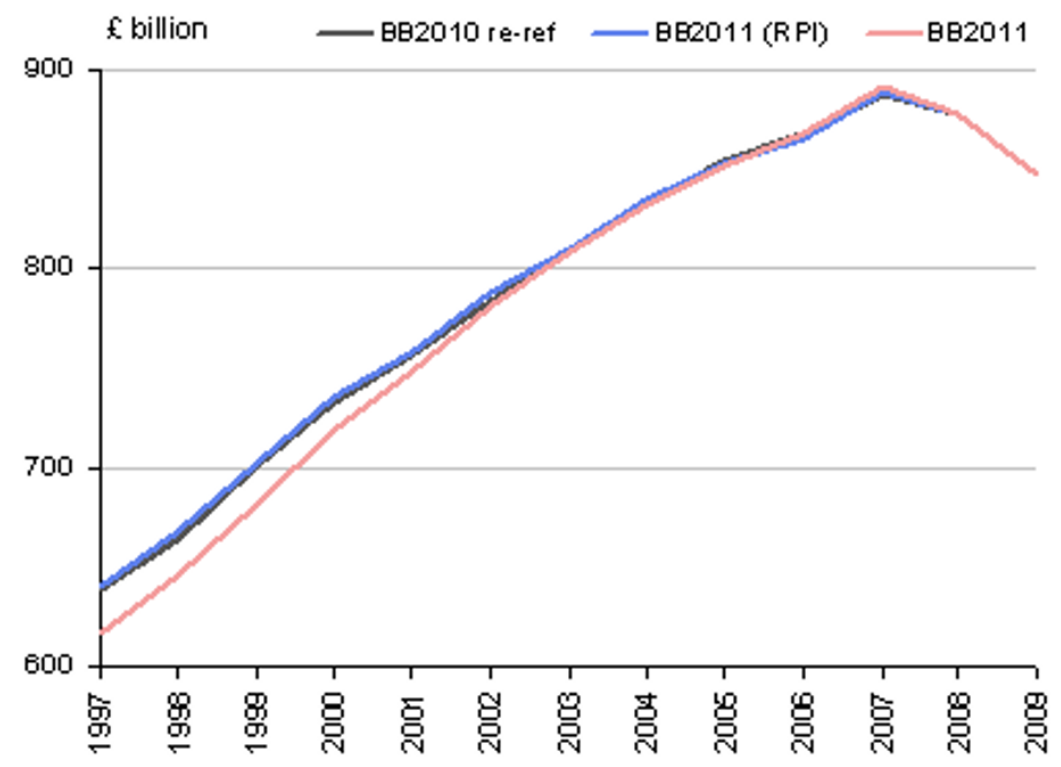

Source: Office for National Statistics

\section{Download chart}

\section{XLS XLS format}

$(13.8 \mathrm{~Kb})$

Moving to the CPI as the price index used for deflation has reduced the CVM in early years, with the largest change in 1997 of 3.8 per cent. However, Figure 4 suggests that the effect of the current price and methodology changes introduced a slight uplift in the CVM level (by around 0.5 per cent in 1997). This is shown where the Blue Book 2011 (RPI) line is above the Blue Book 2010 re-reference line. This shows the current price and method changes partially offset the impact of the deflator change.

Figure $5 \mathrm{a}$ and $5 \mathrm{~b}$ show the all items $\mathrm{CPI}$ and all items RPI (excluding mortgage interest payments and council tax). In Figure 5a it can be seen that the CPI index (not seasonally adjusted) is higher than the RPI for the earlier years. This is consistent with the results shown in Figure 4 because deflating by a higher price index reduces the CVM. Figure $5 b$ shows that in most periods the CPI quarter on quarter growth is lower than that of the RPI. The lower CPI quarter on quarter growth means that the HHFCE CVM Blue Book 2011 growth series in Figure 4 converges with the two other series in 2008.

The differences between the two price indices used for deflation are largest in 1997, the furthest point shown from the base year (in Blue Book 2011 the base year is 2008). The impact of this can be seen in Figure 4 where the Blue Book 2011 CPI deflated CVM estimate is lower. 
Figure 5a and 5b: Comparison of CPI and RPI indices $(2008$ Q1 $=100)$ $5 a$

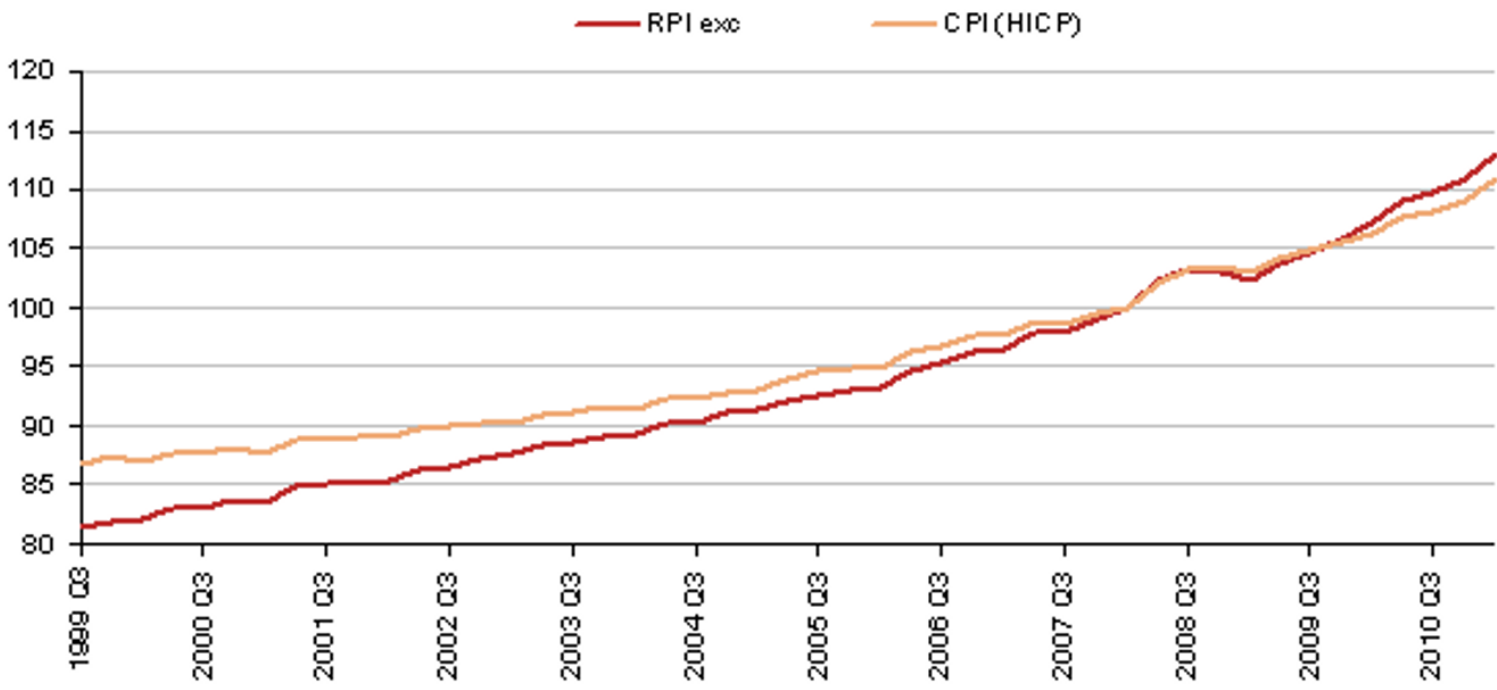

Source: Office for National Statistics

\section{Download chart}

\section{XLS XLS format}

$(16.4 \mathrm{~Kb})$

$5 b$

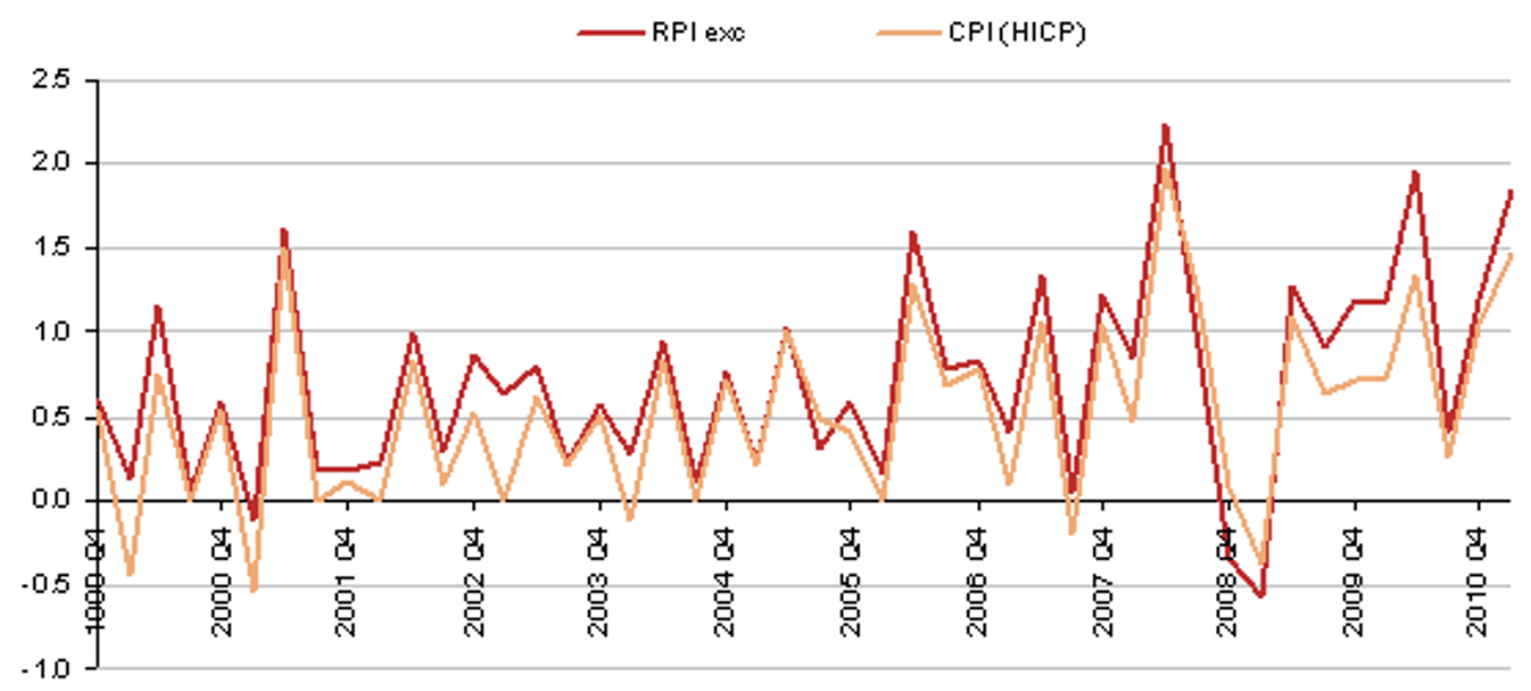

Source: Office for National Statistics 


\section{Download chart}

\section{XLS XLS format}

$(16.4 \mathrm{~Kb})$

The differences between the all items RPI and CPI whilst relevant to the aggregate HHFCE picture conceals a varied picture when an analysis of HHFCE is conducted at the two digit level. An example comparing chained volume measure estimates using the RPI and CPI are provided in Annex $\mathrm{B}$. More information on the differences between the CPI and RPI can be found on the ONS website.

Returning to comparisons with previously published data, the seasonally adjusted chained volume measure levels at an aggregate level (total HHFCE national concept) have been influenced by three factors: the new seasonal adjustment; the changes in Supply and Use adjustments and deflation by the CPI.

Figure 6 shows the quarterly growth rates (seasonally adjusted) for previously published Q1 2011 and Blue Book 2011. The differences in growth rates pre-2000 are a combination of changes brought about by the introduction of X-12-ARIMA; Supply and Use balancing adjustments being redistributed across COICOPs and differences in growth rates between the RPI and CPI. Between 2000 and 2007, it is the latter two reasons that have influenced the growth rate revisions. In 2008 and 2009, the reduction in the Supply and Use balance for HHFCE is an added major factor which has impacted on the revisions to chained volume measure HHFCE growth.

Figure 6: Comparison of chained volume measure growth in Q1 2011 and Blue Book 2011

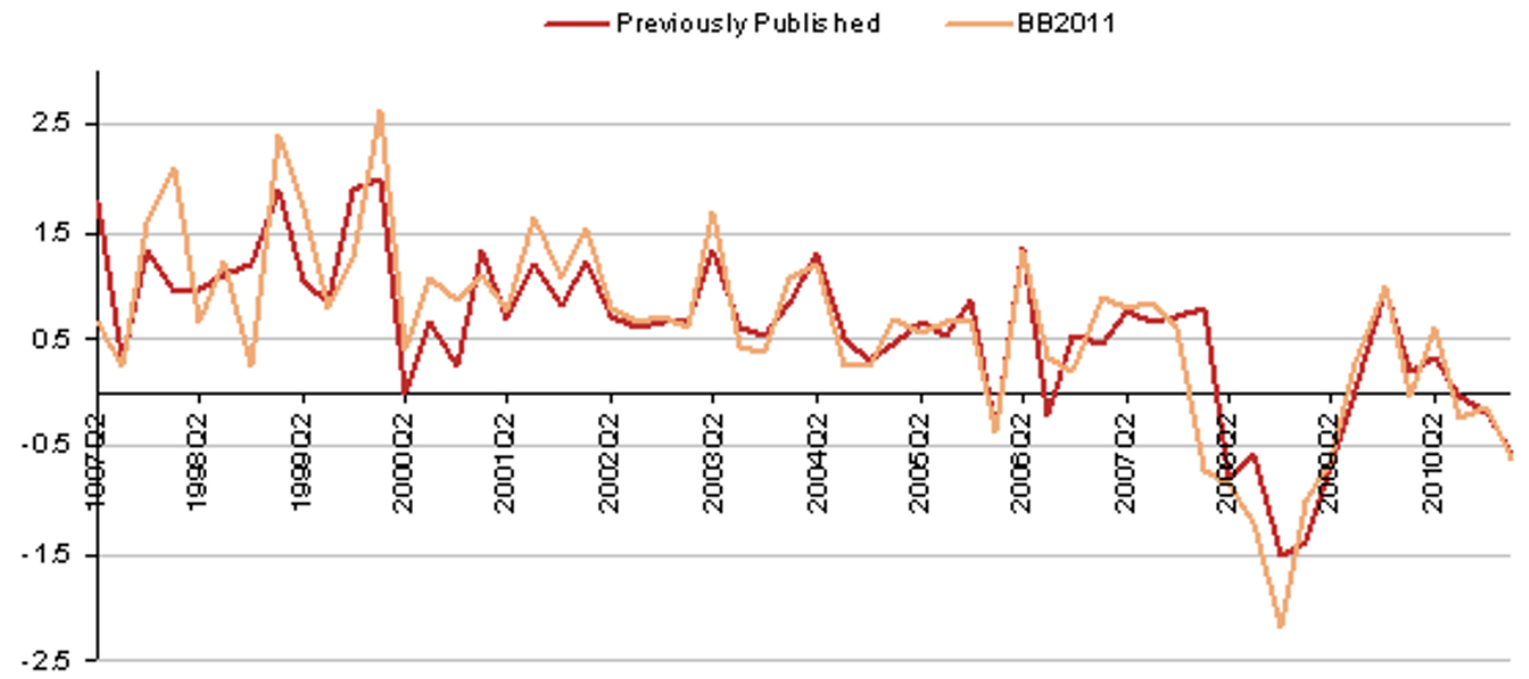

Source: Office for National Statistics 


\section{Download chart}

XLS XLS format

$(16.9 \mathrm{~Kb})$

\section{Impact of Supply and Use balancing process in Blue Book 2011}

The Supply and Use balancing process has not significantly changed aggregate level annual current price HHFCE between 1997 (the first year open for revision) and 2007. However, the balancing process for 2008 and 2009 has taken into account new and revised data sources (for example HMRC income data and new Annual Business Survey data), which has led to a downward revision to previously published data of around 1.5 per cent in both years. The impact of Supply and Use balancing at the total level was shown in Figure 2.

At a more detailed level, when particular goods and services are examined (two and four digit COICOP), the Supply and Use balancing process has had a more varied effect. This is predominantly because the reclassification to SIC 2007 has changed the matching of the estimates produced by Supply and Use balancing to COICOP products. This reclassification has reallocated the total balanced HHFCE across the CPA 2008 products and HHFCE COICOPs. The charts in Annex $\mathrm{C}$ provide some of the largest differences produced in current price terms, for particular goods and services between Blue Book 2011 and previously published Blue Book 2010 estimates.

At the three and four digit level the differences can be more significant - the key examples being: Garments (03.1.2); Domestic and Household Services (05.6.2); Games of Chance (09.3.2); Restaurants, cafes etc (11.1.1); Life Insurance (COICOP 12.5.1) and Other Financial Services (COICOP 12.6.2).

\section{HHFCE Future Plans}

A large development project to improve the estimates of expenditure on imputed rentals and repairs and maintenance for housing (COICOP 04) is planned for the proposed ESA 2010 Eurostat regulation. This work requires a review of existing sources and methods and collaboration with ONS Prices colleagues who are reviewing their measures of actual and owner occupied housing rental price changes.

In addition to this longer term development work, the HHFCE team will aim to incorporate into future Blue Books the results of other analysis projects they have conducted. Analysis has been produced on households' energy consumption (COICOP 04.5), in particular the estimate of gas consumption (COICOP 04.5.2). This will be used to inform balancing adjustments from 2006 onwards. Analysis of the consumption of alcohol (COICOP 02.1) has also been conducted. The HHFCE team are currently analysing external sources and working with the suppliers of data to assess how this can be used to improve the HHFCE estimates.

A new source and method for producing an estimate of expenditure on broadband is currently being tested for inclusion within HHFCE estimates. Given the development of broadband technology any new estimates would only influence HHFCE estimates from 2000 onwards. 


\section{Conclusion}

This article has set out the improvements introduced into the HHFCE dataset as part of Blue Book 2011 production.

It has shown that the current price annual estimates have been revised most in 2008 and 2009. It also presented the reduction in overall Supply and Use adjustments throughout the period 2004 to 2009. The importance of the Supply and Use balancing process was described to put in context the changes and challenges in this Blue Book at a detailed COICOP level. The article also set out future work for the next Blue Book relating to HHFCE developments.

The reasons for changes in chained volume measure level and growth rate estimates were explained at the aggregate HHFCE level. These were the change in level of deflation, the new seasonal adjustment and most notably the impact of deflation using the CPI, but it was also explained that the Supply and Use balancing process influenced chained volume measures.

\section{Acknowledgements}

The authors wish to thank Marianthi Dunn, Stuart Deneen, Steve Drew, Catherine Marks, Gary Brown, Pete Lee, and Darren Morgan for their comments.

\section{Contact Information}

peter.gittins@ons.gov.uk 01633455610

gareth.clancy@ons.gov.uk 01633455889

\section{References}

1. Everett G (2011). 'Content of Blue Book, 2011 edition' Available at: www.ons.gov.uk/ons/rel/ naa1-rd/united-kingdom-national-accounts/2011-edition/content-of-blue-book.pdf

Everett G (2011). 'Methods changes in the 2011Blue Book' Available at: www.ons.gov.uk/ons/ rel/naa1-rd/united-kingdom-national-accounts/method-changes-in-blue-book-2011/ard-methodchanges-in-blue-book-2011.pdf

Hughes J, James G, Evans A and Prestwood D (2009). 'Implementation of Standard Industrial Classification 2007: December 2009 update', Economic and Labour Market Review, December 2009, Volume 3, No 12, pp 51-55. Available at: http://www.ons.gov.uk/ons/rel/elmr/economicand-labour-market-review/no--12--december-2009/economic---labour-market-review.pdf

Correspondence table: COICOP 1999 - CPA 2008 http://ec.europa.eu/eurostat/ramon/relations/ index.cfm?TargetUrl=LST_REL\&StrLanguageCode=EN\&IntCurrentPage=3 
Drew S (2011), 'Deflation improvements in the UK national accounts - Steve Drew Office for National statistics August 2011' , Available at: http://www.ons.gov.uk/ons/rel/naa1-rd/nationalaccounts-concepts--sources-and-methods/august-2011/deflation-improvements-in-the-uknational-accounts.pdf

Definition of Classification of Individual Consumption by Purpose http://epp.eurostat.ec.europa.eu/statistics explained/index.php/ Glossary:Classification_of_individual_consumption_by_purpose_(COICOP)

Definition of Classification of Products by Activity http://epp.eurostat.ec.europa.eu/portal/page/ portal/cpa 2008/documents/CPA2008introductoryguidelinesEN.pdf

More information on the differences between $\mathrm{CPI}$ and $\mathrm{RPI}$

http://www.ons.gov.uk/ons/guide-method/user-guidance/prices/cpi-and-rpi/index.html 


\section{Annex A. Example Comparison of Calculation levels Pre and Post Blue Book 2011}

This table shows the current breakdown of the COICOP group 01.1.1 - Bread and cereals pre and post Blue Book 2011

\begin{tabular}{|c|c|c|c|}
\hline \multicolumn{2}{|c|}{ Current breakdown of 01.1.1 } & \multicolumn{2}{|c|}{$\begin{array}{l}\text { Breakdown of 01.1.1 from Blue } \\
\text { Book } 2011\end{array}$} \\
\hline COICOP & Description & COICOP & Description \\
\hline 01.1 .1 & Bread and cereals & 01.1 .1 & Bread and cereals \\
\hline $01.1 .1 \mathrm{~N} 1$ & Rice & $01.1 .1 \mathrm{~N} 1$ & $\begin{array}{l}\text { Bread, cakes \& } \\
\text { non-chocolate } \\
\text { biscuits }\end{array}$ \\
\hline $01.1 .1 \mathrm{~N} 2$ & $\begin{array}{l}\text { Bread and non- } \\
\text { chocolate biscuits }\end{array}$ & $01.1 .1 \mathrm{~N} 2$ & Chocolate biscuits \\
\hline $01.1 .1 \mathrm{~N} 3$ & Chocolate biscuits & $01.1 .1 \mathrm{~N} 3$ & $\begin{array}{l}\text { Cereals \& cereal } \\
\text { products }\end{array}$ \\
\hline $01.1 .1 \mathrm{~N} 4$ & Pasta products & & \\
\hline $01.1 .1 \mathrm{~N} 5$ & $\begin{array}{l}\text { Pastry-cook } \\
\text { products }\end{array}$ & & \\
\hline $01.1 .1 \mathrm{~N} 6$ & Cereals & & \\
\hline $01.1 .1 \mathrm{~N} 7$ & Cereal products & & \\
\hline \multicolumn{2}{|c|}{$\begin{array}{l}\text { Deflation is currently done at the lower } \\
\text { level with individual RPI series for } \\
\text { each product }\end{array}$} & \multicolumn{2}{|c|}{$\begin{array}{l}\text { Deflation will be done at the 01.1.1 } \\
\text { level using the CPI for 01.1.1 }\end{array}$} \\
\hline
\end{tabular}

Table source: Office for National Statistics

Download table

XLS XLS format

In the column on the left hand side there are seven sub-categories that aggregate into 01.1.1. Previously the HHFCE system calculated current price estimates below the published level for each of these categories. On the right hand side there are only three sub-categories. It is only these that are produced in the HHFCE system from Q2 2011 onwards.

Previously, each of the categories on the left hand side were deflated to produce chained volume measures. As from Blue Book 2011 (Q2 2011) deflation takes place at the 01.1.1 Bread and cereals level. 


\section{Annex B. Examples: Comparison of deflation using RPI and CPI at a detailed level.}

The analysis conducted in this Annex uses Blue Book 2011 data to show the impact of using the $\mathrm{CPI}$ instead of the RPI. The model is currently only configured to produce analysis up to 2009.

One of the largest impacts on a COICOP takes place in 03 'Clothing and Footwear'. This is shown in Figure 7, where the difference in 1997 between the Blue Book 2011 CVM estimate deflated using the RPI, and deflated by the CPI is $£ 6.1$ billion (falling to $£ 1.4$ billion in 2007). For this item of household expenditure deflating by the CPI has lowered the CVM in most years.

\section{Figure 7: Comparison of Clothing and Footwear CVMs}

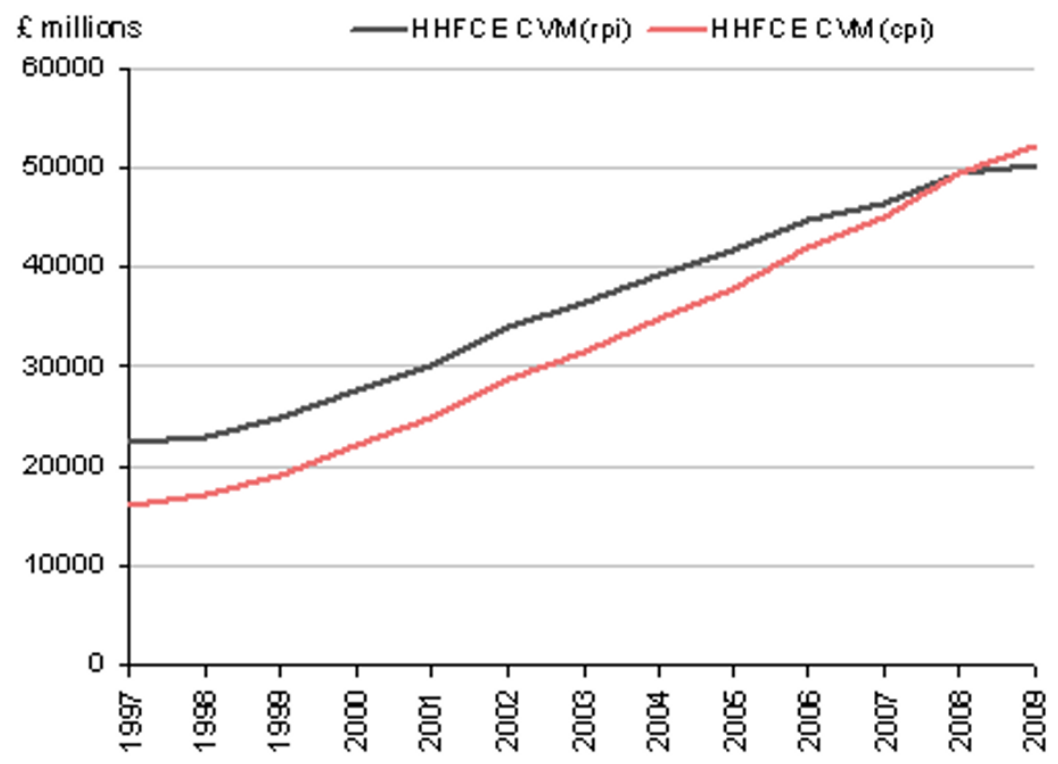

Source: Office for National Statistics

\section{Download chart}

\section{XLS XLS format}

$(13.8 \mathrm{~Kb})$

The impact of deflation by the CPI was similar for following COICOPs: 04 Housing; 05 Household goods and services; 07 Transport; 09 Recreation; and 12 Miscellaneous. The use of the CPI lowered the CVM by more than one billion in comparison to deflation using the RPI for these COICOPs.

It is worth considering the impact a little more at the detailed COICOP level, which for a number of goods and services is the level at which deflation takes place. At the two digit level Clothing and Footwear was heavily affected by the move to CPI deflation. Analysis at the four digit level shows that nearly all of this change is caused by COICOP 3.1.2 Garments (Figure 8). This change was driven by the difference between the RPI deflator previously used and the current CPI deflator shown in Figure 9. 
Figure 8: Comparison of Garments CVMs

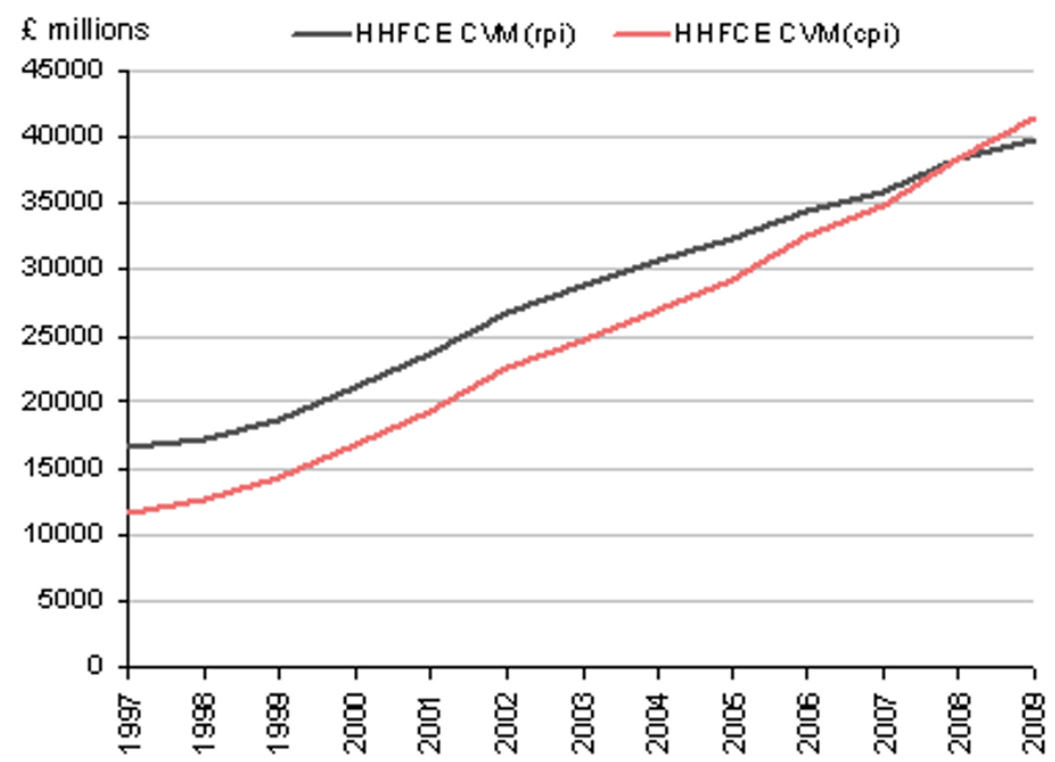

Source: Office for National Statistics

\section{Download chart}

XLS XLS format

$(13.8 \mathrm{~Kb})$

Figure 9: Comparison of Garments RPI and CPI deflators

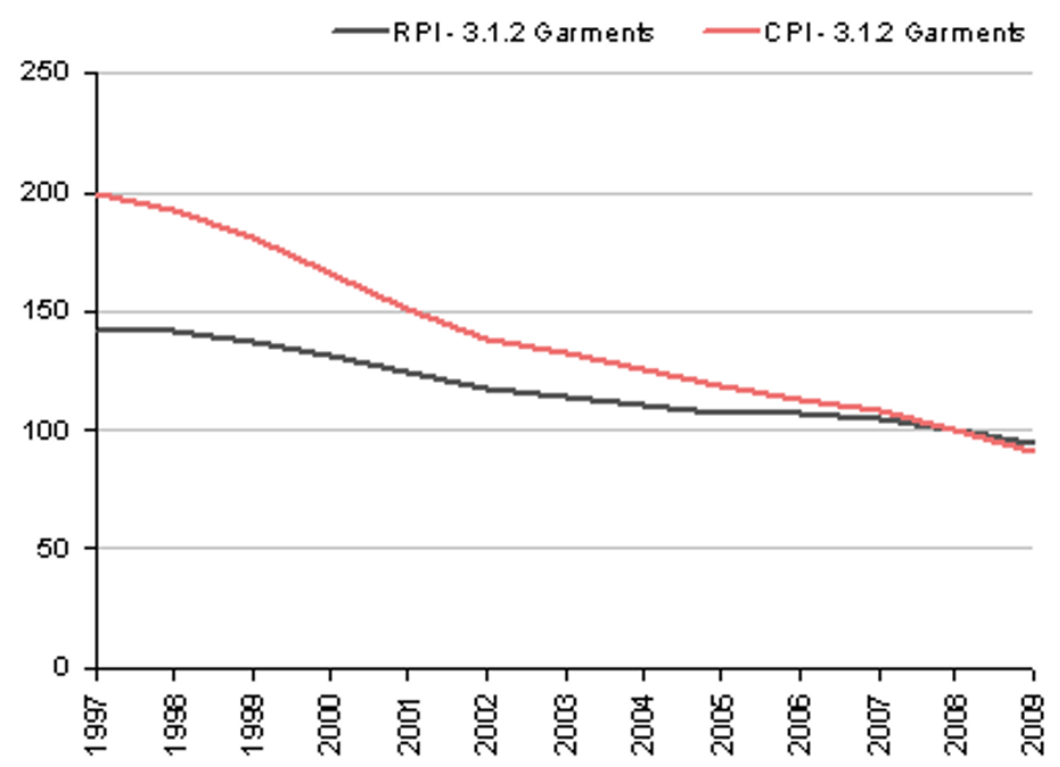

Source: Office for National Statistics

\section{Download chart}

\section{XLS XLS format}

$(13.8 \mathrm{~Kb})$ 
However, at the two digit COICOP level the change in deflator did not always reduce the household expenditure CVM levels. When COICOP 08 'Communication' was deflated using the CPI the level is increased. A similar effect was seen in 10 'Education'.

A number of COICOPs have been affected to a lesser extent by the move to CPI deflation. These include: 01 Food and drink; 02 Alcohol and tobacco; 06 Health and 11 Restaurants and hotels.

\section{Annex C. Impact of Supply and Use}

Analysis in this Annex shows the current price changes in HHFCE estimates as a result of the Supply and Use balancing (SU) changes through re-classification to SIC 2007 and the re-distribution of expenditure across CPA 2008 products. In Blue Book 2011 National Accounts estimates were balanced using the input-output framework and Supply and Use tables up to 2009.

\section{Garments (COICOP 03.1.2)}

Figure 10 shows the downward adjustment incorporated into household expenditure estimates for garments in earlier years as a result of SU balancing. The main household expenditure source for this COICOP is the Retail Sales Inquiry, information from Trade in Goods and the Annual Business Survey used in the production approach has informed a decision to reduce household expenditure over this period.

Figure 10: Comparison of Blue Book 2010 and 2011 Garments Estimates

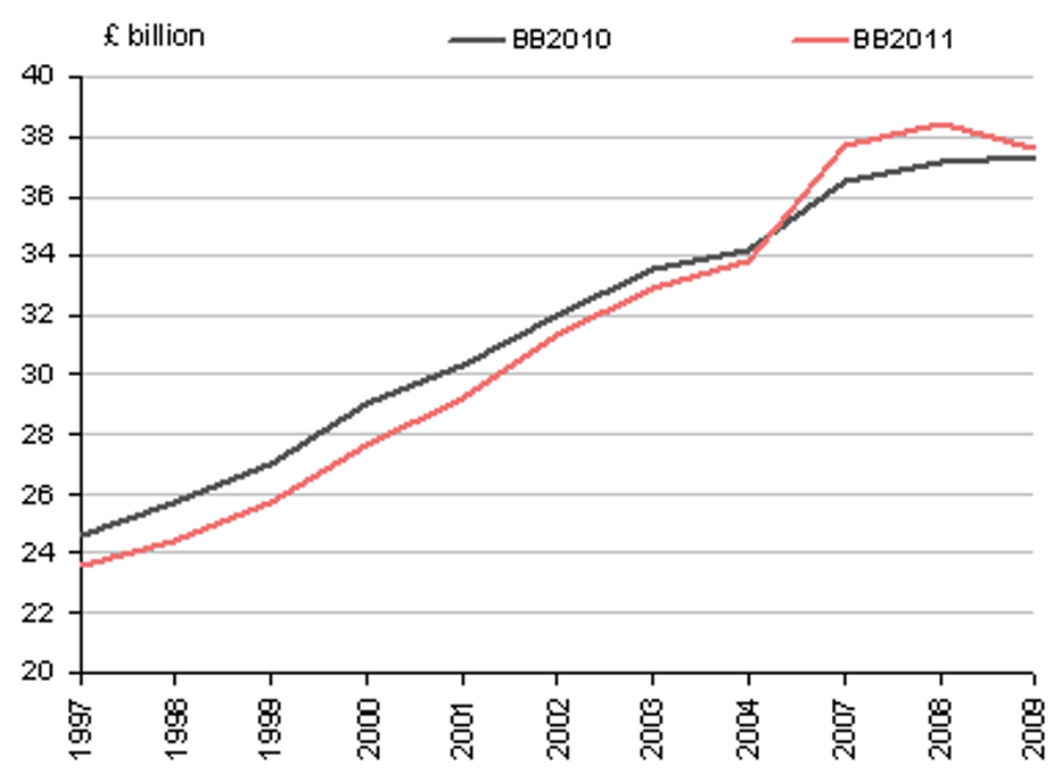

Source: Office for National Statistics

\section{Download chart}

XLS XLS format

$(13.8 \mathrm{~Kb})$ 


\section{Domestic and Household Services (COICOP 05.6.2)}

Figure 11 shows HHFCE levels for domestic and household services have been revised upwards from 1997 onwards. This is a result of balancing the main HHFCE data based on the Living Costs and Food Survey with estimates derived from HMRC tax data for the Income approach to measuring GDP.

Figure 11: Comparison of Blue Book 2010 and 2011 Domestic and household services estimates

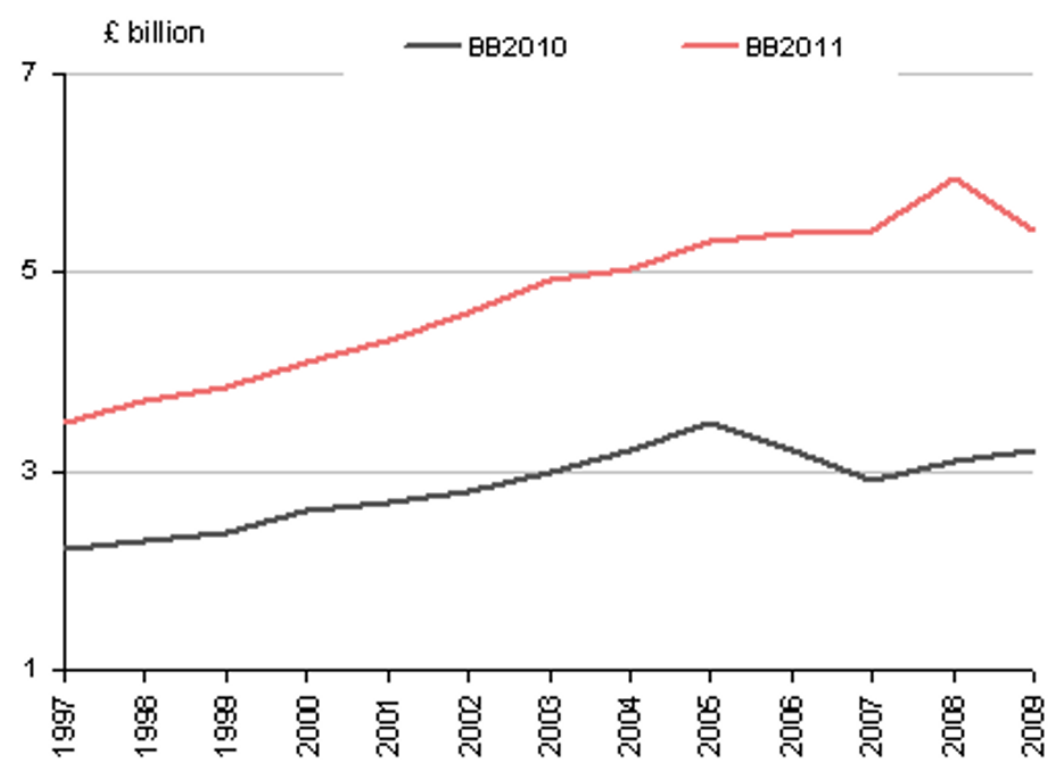

Source: Office for National Statistics

\section{Download chart}

\section{XLS XLS format}

$(13.8 \mathrm{~Kb})$

\section{Games of chance (COICOP 09.4.3)}

Figure 12 shows that the HHFCE levels for games of chance at current prices between 1997 and 2005 have been revised down, and upwards after 2006. The HHFCE estimates are based on information collected from the Gaming Commission, Office of the Lottery Regulator and the Living Costs and Food survey. These estimates are balanced against information from the Annual Business Survey and HMRC. The collection of gambling industry data for Supply and Use balancing and household expenditure is complicated by the number of international providers of gambling services, which are not always covered in source data. 
Figure 12: Comparison of Blue Book 2010 and 2011 Games of chance estimates

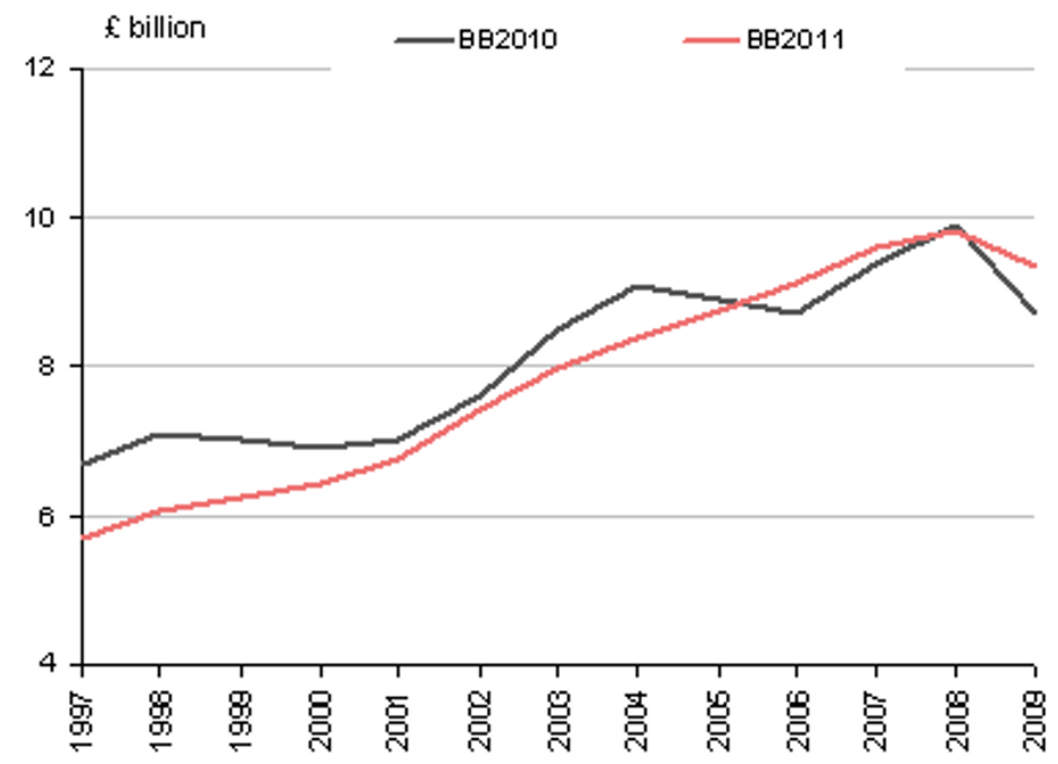

Source: Office for National Statistics

\section{Download chart}

XLS XLS format

$(13.8 \mathrm{~Kb})$

Restaurants, cafes etc. (COICOP 11.1.1)

Figure 13 shows that HHFCE estimates at current prices for "restaurants, cafes etc" have been revised down in all years. The changes in the household expenditure estimates in COICOP 11.1.1 are a combination of balancing the HHFCE data against industry output data for restaurants and alcohol companies (on-trade sales) and the removal of Supply and Use adjustments introduced in previous Blue Books. 
Figure 13: Comparison of Blue Book 2010 and 2011 Restaurants, cafes estimates

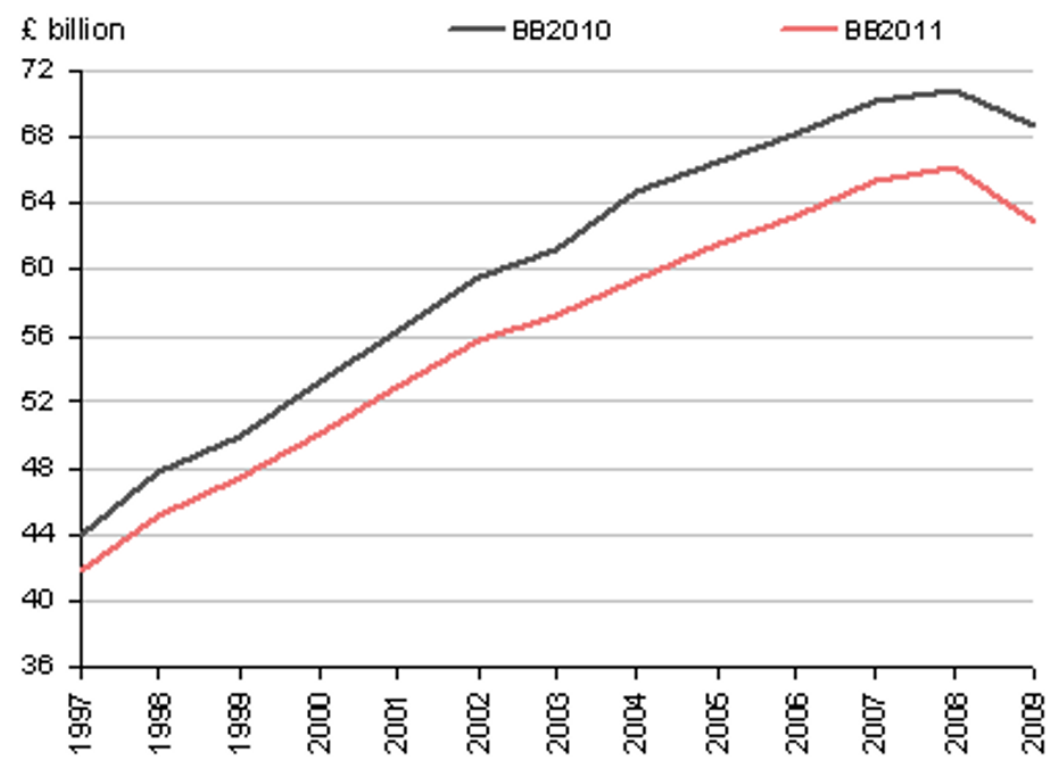

Source: Office for National Statistics

\section{Download chart}

XLS XLS format

$(13.8 \mathrm{~Kb})$

(C) Copyright Crown 2011 